
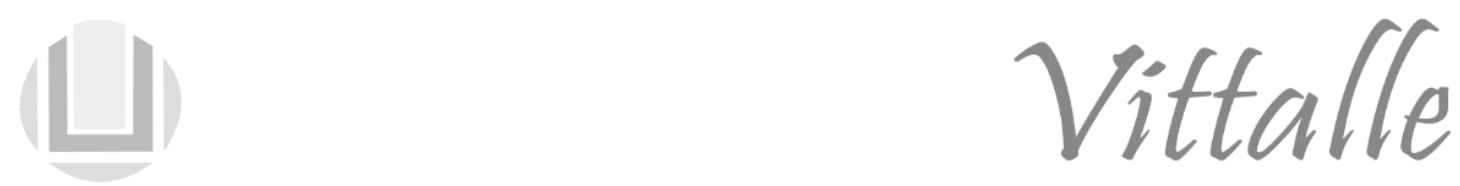

\title{
Drenagem torácica
}

\author{
Marina Ilha de Azambuja*, Miguel Angelo Martins de Castro Junior
}

Faculdade de Medicina, Universidade Federal do Rio Grande, Rio Grande, RS, Brasil

\section{Palavras-chave: \\ Cavidade torácica; \\ Procedimento cirúrgico; \\ Competência Clínica; \\ Ensino; Medicina.}

\section{Keywords:}

Thoracic Cavity;

Surgical Procedures;

Clinical Competence;

Teaching; Medicine.

\section{RESUMO}

A drenagem torácica é um procedimento comum na prática diária realizada para drenar fluido, sangue ou ar de cavidade pleural. A drenagem efetiva requer um dreno posicionado adequadamente e um sistema de drenagem unidirecional hermético para manter a pressão intrapleural subatmosférica. Isso permite drenagem do conteúdo pleural e reexpansão do pulmão. Este capítulo aborda conceitos essenciais da drenagem torácica, com o objetivo de organizar o suporte téorico para a realização do procedimento.

Thoracic drainage

\section{Introdução}

Drenagem torácica é um procedimento cirúrgico que consiste em introduzir um dreno, através da parede torácica, na cavidade pleural, com o objetivo de esvaziamento do conteúdo líquido ou gasoso retido (1). Pode ocorrer em situações patológicas (p. ex., pneumotórax, hemotórax, empiema e quilotórax) ou pós-procedimento que viole a cavidade (p. ex., cirurgia cardíaca ou torácica) (2). Ademais, trata-se de um dos procedimentos cirúrgicos mais executados na prática clínica; é relativamente simples, todavia, quando negligenciado acarreta danos ao paciente desproporcionais à simplicidade da técnica (3). A drenagem efetiva requer um dreno adequadamente posicionado e um sistema de drenagem hermético e unidirecional para manter a pressão intrapleural subatmosférica, o que permite drenagem do conteúdo pleural e reexpansão do pulmão (1-6).

Diante do exposto, este capítulo aborda aspectos essenciais sobre a drenagem torácica compreendendo uma revisão bibliográfica relevante e atual para a realização com sucesso dessa habilidade médica.

\section{Princípios do funcionamento da drenagem}

A drenagem torácica tem seus princípios baseado no mecanismo ventilatório pulmonar.

\footnotetext{
*Autor correspondente: marina.ilha.azambuja@gmail.com (Azambuja M. I.)
} 
Em pessoas sadias, a pressão intrapleural é sempre negativa, variando de -2 a $-8 \mathrm{cmH}_{2} \mathrm{O}$ $(1,2)$. Em situações extremas, como na tosse e na inspiração profunda, tal variação pode exceder $50 \mathrm{cmH}_{2} \mathrm{O}$ (2). Na inspiração, por meio da elevação dos arcos costais e do abaixamento do diafragma, ocorre o aumento do volume da caixa torácica, diminuindo assim a pressão intrapleural, de modo que o ar flui para o interior dos pulmões passivamente; o contrário ocorre na expiração (2). Devido a estas variações de pressões, o sistema de drenagem não pode ser simplesmente aberto para o ar atmosférico, uma vez que permitiria a entrada de ar na cavidade e dificultaria a expansão pulmonar (2,3).

O sistema de drenagem mais utilizado é composto por (Figura 1) (2):

- respiros do dreno;

- conexões intermediárias e extensões;

- frasco selo de água.

A parte distal da extensão intermediária encontra-se mergulhada $2 \mathrm{~cm}$ dentro de uma coluna de água presente no frasco coletor. O conteúdo retido passa pelo sistema de drenagem em direção ao cilindro coletor quando houver um aumento da pressão intrapleural mínima de $2 \mathrm{cmH}_{2} \mathrm{O}$, suficiente para vencer a resistência da coluna de água.

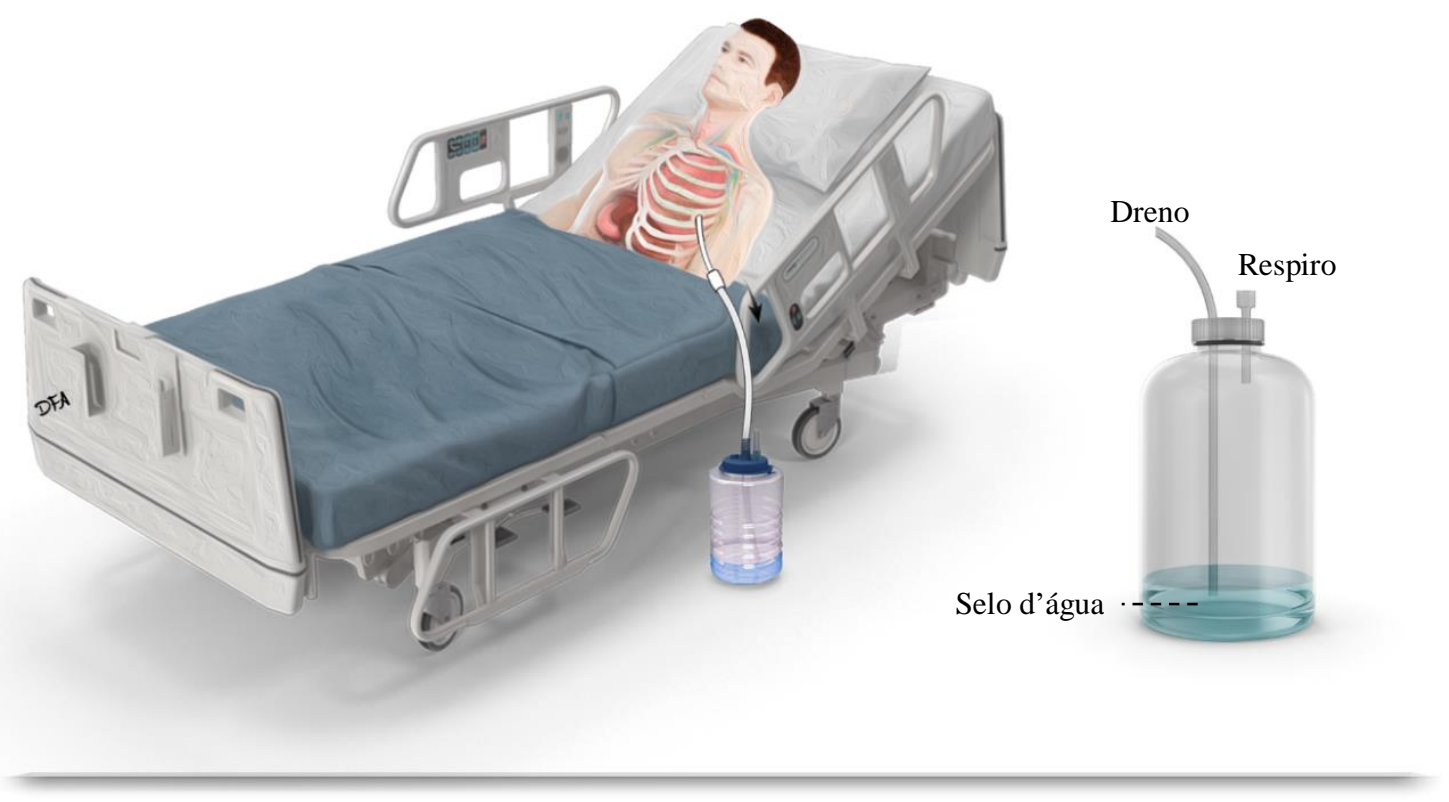

Figura 1 - Sistema de drenagem convencional com selo d'água.

Paciente no leito com dreno de tórax em selo d'água. Destaque para o cilindro coletor que deve ser preenchido com soro fisiológico até cobrir $2 \mathrm{~cm}$ da extremidade do dreno.

A coluna de água impede, na inspiração, o retorno do conteúdo drenado, desde que o frasco esteja posicionado corretamente (cerca de $10 \mathrm{~cm}$ abaixo do tórax do paciente). No caso de derrames pleurais com drenagem de grandes volumes, devido ao acúmulo de líquido no frasco coletor, pode-se formar uma coluna líquida maior do que a capacidade expiratória do paciente, geralmente $20 \mathrm{~cm}$ de solução, dificultando o escoamento do conteúdo drenado. Nesses casos, para evitar troca constante do frasco coletor e/ou parada da drenagem, é indicado a drenagem de duplo frasco (Figura 2) $(2,5)$. 


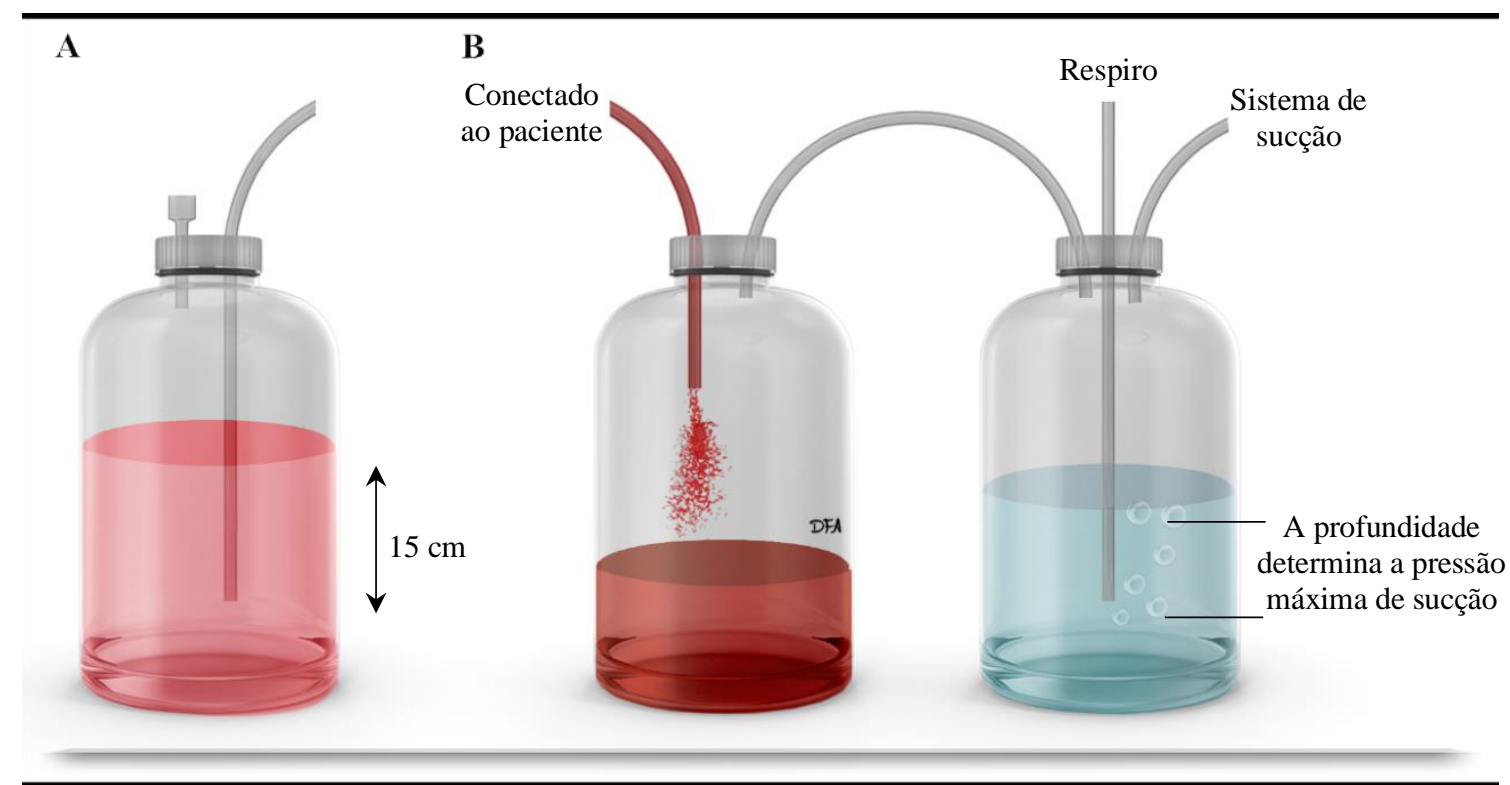

Figura 2 - Sistemas de drenagem.

A. Sistema convencional incorreto: dreno de tórax em selo dágua com coluna líquida maior que $20 \mathrm{~cm}$ devido ao acúmulo de conteúdo drenado, impedimento o escoamento do líquido e o adequado funcionamento do sistema. B. Correto: sistema de drenagem em duplo frasco, permitindo que a pressão de sucção seja a mesma, independente da quantidade de líquidos drenada para o primeiro frasco.

\subsection{Drenagem valvular}

A drenagem valvular (válvula Heimlich) é uma alternativa aos frascos coletores, em especial, para pneumotórax. A válvula é constituída por um tubo de plástico de $10 \mathrm{~cm}$ de comprimento, no interior do qual estão duas lâminas de borracha com íntimo contato entre si (7).

\subsubsection{Vantagens}

As vantagens incluem:

- permite maior mobilidade ao paciente;

- não necessita de pinçamentos durante o transporte;

- mantém seu funcionamento independente de sua posição ou nível;

- fácil entendimento e manutenção;

- mais segurança e facilidade de higienização.

\subsubsection{Desvantagens}

As desvantagens incluem:

- menor controle de escape aéreo;

- inviabiliza o uso de aspiração contínua;

- maior custo.

\subsection{Aspiração contínua da cavidade pleural}

Indicada em casos de expansão pulmonar incompleta. A pressão negativa no sistema é dada por um frasco regulador de três bocas que permite uma pressão de aspiração contínua, sendo uma saída para o vácuo, outra conectada ao frasco coletor e outra ao 
respiro. Uma das bordas do frasco regulador contém o respiro longo que em uma extremidade comunica-se com a atmosfera e outra encontra-se mergulhada entre 10 e 20 cm (Figura 3) (4-6).

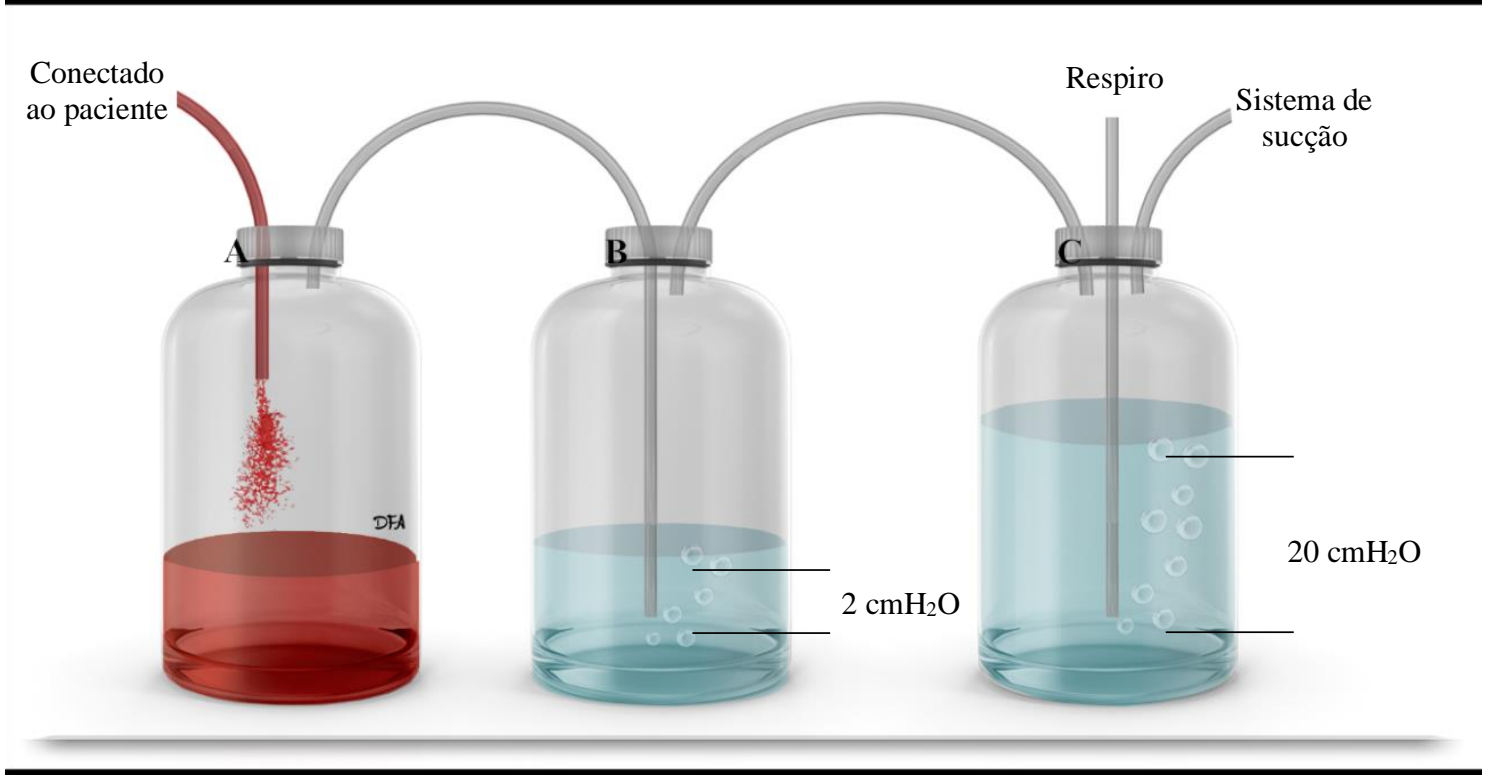

Figura 3 - Sistema de drenagem com aspiração contínua da cavidade pleural.

A. Primeiro frasco conectado diretamente ao dreno de tórax. B. Segundo frasco que deve ser preenchido com soro fisiológico até cobrir $2 \mathrm{~cm}$ da extremidade do dreno. C. Terceiro frasco com respiro preenchido com $20 \mathrm{~cm}$ de soro fisiológico conectado a um sistema de sucção (aspirador).

\section{Características dos componentes da drenagem}

\subsection{Dreno}

Os drenos do tórax vêm em uma variedade de tamanhos adequados para uma variedade de propósitos (tipicamente 10-40 Ch) e podem ser inseridos através de uma incisão cirúrgica aberta (toracostomia) ou usando a técnica de Seldinger incorporando um fioguia e sistema dilatador. Os drenos devem ter as seguintes características:

- tubular multiperfurado pela maior superfície de drenagem e menor chance de obstrução;

- $\quad$ siliconizado, pois dificulta a aderência de coágulos;

- consistência firme pela menor chance de colapsar e de formar coágulos; deve-se evitar o uso de drenos rígidos que provocam dor e podem lesar o pulmão;

- radiopaco ou com linha radiopaca, o que permite confirmar, por radiografia, se a última perfuração do dreno está posicionada adequadamente na cavidade pleural;

- fixação deve ser feita com fio inabsorvível na pele, além de fixação adicional por bailarina para evitar deslocamentos que alterem a posição do dreno $(1,2,4-6)$;

- calibre em adultos:

- $36 \mathrm{~F}\left(3 / 8^{\prime}\right)$ em hemotórax ou derrames espessos;

- $28 \mathrm{~F}\left(1 / 4^{\prime}\right)$ em pneumotórax ou derrames fluidos.

- calibre em crianças:

- $16 \mathrm{~F}$ em recém-nascidos;

- $22 \mathrm{~F}$ com 1 ano de idade. 


\subsection{Extensão intermediária e conector}

O conector é uma peça cilíndrica preferencialmente de material transparente. A extensão intermediária é uma peça tubular, de material transparente plástico ou de látex, que conecta o dreno até o frasco coletor. É de extrema importância que o diâmetro interno do conector seja o mesmo do restante do sistema para evitar qualquer dificuldade de passagem $(2,5)$.

\subsection{Frasco coletor}

Frasco de vidro ou plástico transparente e graduado para permitir o controle do volume drenado. Em geral, a capacidade do frasco é de $2000 \mathrm{~mL}$. Devem ser preenchidos com soro até $2 \mathrm{~cm}$ acima do tubo ligado ao conector $(2,5)$.

\section{Indicações e contraindicações}

A indicação correta é feita por meio de uma combinação entre patologia e mecanismo de lesão, exame clínico e imagem radiológica. Mais recentemente, o uso da ultrassonografia à beira do leito, guiando a inserção do dreno, está associado a menores taxas de complicações e é particularmente útil para efusões e empiema, pois o diafragma pode ser localizado e a presença de loculações e espessamento pleural definido (4-7).

As contraindicações podem ser absolutas ou relativas conforme listadas a seguir (Quadro 1). A única contraindicação absoluta para realização do procedimento pulmão estar densamente aderido à parede torácica em todo o hemitórax.

A solicitação da contagem de plaquetas e do tempo de protrombina só é recomendada em pacientes com fatores de risco conhecidos. Não há evidências publicadas de que a coagulação sanguínea ou a contagem de plaquetas anormais afetem as complicações hemorrágicas da inserção do dreno torácico. No entanto, sempre que possível, é uma boa prática corrigir qualquer defeito de coagulopatia ou plaquetas antes da inserção do dreno. Para a inserção eletiva do dreno do tórax, a varfarina deve ser interrompida e deve-se aguardar o tempo necessário para que seus efeitos sejam resolvidos. 
Quadro 1 - Indicações e contraindicações para drenagem pleural tubular.

\section{INDICAÇÕES DEVIDO TRAUMA TORÁCICO OU DERRAME PLEURAL}

\section{INDICAÇÕES}

\section{Trauma torácico}

Em qualquer paciente com ventilação com pressão positiva

Pneumotórax (Pntx) hipertensivo após descompressão com toracocentese

Pntx recorrente ou persistente após aspiração simples com toracocentese (> 2,5 litros)

Pntx expontâneo secundário, de grande volume, em paciente com mais de 50 anos

Pntx iatrogênico (deve ser avaliado quanto ao seu tamanho, sintomas e comorbidades)

Pntx pequeno (até 1/3 da cavidade), hemotórax pequeno (até $350 \mathrm{~mL}$ ) e hemopneumotórax pequeno desde que sintomáticos ou progressivos ao exame radiológico

Pntx, hemotórax ou hemopneumotórax médio ou grande

Doente in extremis com sinais de trauma torácico

Pntx, hemotórax ou hemopneumotórax espontâneos ou iatrogênicos

\section{Derrame pleural}

Neoplásico (principalmente sintomático ou recorrente)

Sintomático e recorrente

Empiema e derrame pleural parapneumônico complicado

Pós-procedimento cirúrgico com abertura da pleura

Quilotórax

\section{CONTRAINDICAÇÕES}

Pulmão densamente aderido à parede torácica em todo o hemitórax (Absoluta)

Sítio cirúrgico com sinais de infecção

Falta de cooperação do paciente

Discrasia sanguínea não corrigida

Fonte - Elaborado pelos autores com adaptações $(1,6)$.

\section{Preparação}

Antes de iniciar a inserção do tubo torácico, o procedimento deve ser explicado completamente ao paciente e o consentimento registrado de acordo com as diretrizes nacionais (1). A menos que existam contraindicações para o seu uso, a medicação prévia (benzodiazepínico ou opióide) deve ser administrada para reduzir a angústia do paciente (6).

\subsection{Checklist}

Materiais necessários para drenagem torácica:

- par de luvas estéril;

- avental estéril;

- gorro e propés; 
- máscara cirúrgica;

- $\quad$ óculos de proteção;

- $\quad$ pacote de gaze estéril;

- cuba pequena para antissepsia;

- pinça para antissepsia;

- cuba rim para descarte;

- clorexidina alcoólica $0,5 \%$;

- campo fenestrado estéril;

- $\quad$ agulha de aspiração 40 x 1,2 mm (18G);

- agulha de infiltração 30 x 0,73 mm (22G);

- $\quad$ seringa de 5 ou $10 \mathrm{~mL}$ para anestesia local;

- lidocaína 1 ou $2 \%$ com ou sem vasoconstritor;

- pinça Kelly curva;

- tesoura Metzenbaum $(20 \mathrm{~cm})$;

- bisturi com lâmina $n^{\circ} 15$;

- dreno de tórax;

- $\quad$ sistema de drenagem fechado;

- fio inabsorvível.

- material para curativo.

\subsection{Posicionamento do paciente}

Decúbito semissentado, ligeiramente rotado, com o braço do lado da lesão por trás da cabeça para expor a região axilar. A inserção deve ser no "triângulo de segurança" (Figura 4).

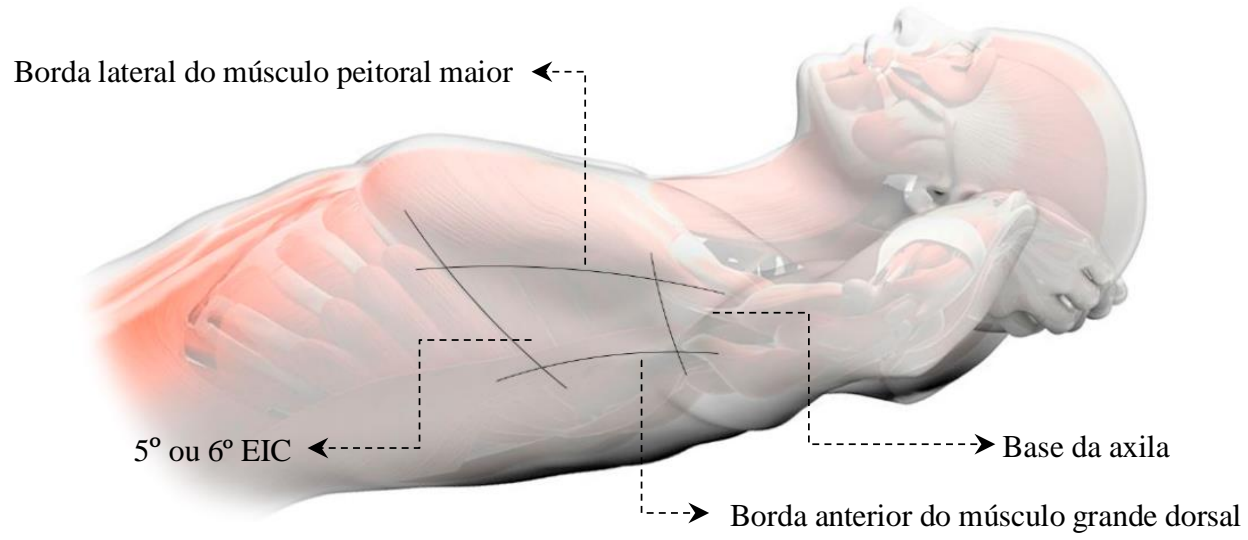

Figura 4 - Posicionamento e "triângulo de segurança".

"Triângulo de segurança" delimitado pela borda anterior do músculo grande dorsal, borda lateral do músculo peitoral maior, linha superior ao nível horizontal do mamilo $\left(5^{\circ}\right.$ ou $6^{\circ}$ EIC) e o ápice abaixo da axila.

Esta posição minimiza o risco de lesão das estruturas subjacentes, como a artéria mamária interna, e evita danos ao tecido muscular e glandular da mama. A incisão deve ser feita no $4^{\circ}$ ou $5^{\circ}$ espaço intercostal, sendo o ponto de referência externo igual ou 
ligeiramente acima do nível do mamilo nos homens. A inserção neste local é ideal devido à parede torácica relativamente fina e à distância do diafragma, que durante a expiração pode facilmente atingir o sexto espaço intercostal. $(6,7)$.

\subsection{Confirmar local de inserção da drenagem}

Um tubo torácico não deve ser inserido sem orientação adicional da imagem se o ar ou o fluido livre não puderem ser aspirados com uma agulha no momento da anestesia. Uma radiografia de tórax deve estar disponível no momento da inserção do dreno, exceto no caso de pneumotórax hipertensivo (6).

\subsection{Técnica asséptica}

Deve ser empregada durante a inserção do dreno. Uma metanálise sugeriu que, na presença de traumatismo torácico (penetrante ou contundente), o uso de antibióticos profiláticos reduz o risco absoluto de empiema em 5,5 a 7,1\% e de todas as complicações infecciosas em 12,1 a 13,4\%. Esse estudo recomenda o uso de antibióticos profiláticos (cefalosporinas ou clindamicina) em casos de trauma (3).

\subsection{Anestesia, incisão e dissecção}

Anestesia local com deve ser feita com lidocaína infiltrando o espaço intercostal escolhido. O bloqueio anestésico deverá cobrir toda a espessura da parede torácica.

A técnica preferida é a incisão aberta com dissecação brusca de tecidos profundos com pinça ou inserção guiada pelo introdutor do dreno (1). Uma incisão de 1,5 a $2 \mathrm{~cm}$ de extensão deve ser feita paralelamente à costela e com uma pinça hemostática curva divulsiona-se o subcutâneo e os músculos intercostais penetrando na cavidade pleural. Com o dedo indicador deve-se fazer, delicadamente, uma exploração digital (7).

\subsection{Inserção do tubo}

Uma extremidade distal do tubo é inserida na cavidade pleural através da incisão subcutânea com o auxílio de uma pinça curva presa a sua ponta. Avança-se o tubo inclinando a posição da ponta para cima e posteriormente. A última fenestra do tubo deve ficar no espaço pleural $(1,4-6)$.

\subsection{Síntese e curativo}

A pequena incisão é fechada com um ponto em "U", circundando o dreno. Conecta-se a extremidade distal do dreno com o sistema de drenagem. Uma vez que o tubo é ligado, caso haja um pneumotórax, o borbulhamento poderá ser visto. A oscilação da coluna líquida é obrigatória e indica o correto posicionamento do dreno na cavidade pleural $(1,4-6)$.

\subsection{Radiografia de tórax}

Usada para confirmar a coleção e o correto posicionamento do dreno. Entretanto pode ser dispensável caso o dreno esteja funcionando corretamente e houver sinais clínicos de expansão pulmonar (1,4-6). 


\section{Resumo da técnica para a colocação do dreno}

- paciente em posição semissentada;

- $\quad$ antissepsia e assepsia;

- anestesia local com lidocaína no $5^{\circ}$ ou $6^{\circ}$ EIC, na linha axilar média;

- incisão transversal com bisturi na borda superior da costela inferior;

- dissecção com pinça Kelly curva, divulsionando as fibras musculares até perfurar a pleura;

- $\quad$ exploração digital;

- passagem do dreno delicadamente, deixar os orifícios no espaço pleural;

- conectar o dreno ao frasco;

- fixar o dreno e fazer bailarina;

- verificar borbulhamento ou escoamento líquido;

- curativo oclusivo.

\section{Retirada do dreno}

\subsection{Critérios para retirada}

As indicações para remoção do dreno são variáveis na literatura. Atualmente, não há evidências sólidas do momento ideal para retirada do dreno. Em geral, os critérios vão de acordo com às preferências do profissional:

- melhora clínica e da ausculta pulmonar;

- fluxo de drenagem líquida menor que 150 a $200 \mathrm{~mL} / \mathrm{dia}(2 \mathrm{~mL} / \mathrm{kg} / \mathrm{dia})$;

- ausência de fuga aérea por 24 a 48 horas com evidência radiológica de expansão pulmonar;

- resolução de intercorrência pleural;

- tempo máximo de 10 dias de drenagem, mesmo quando não resolvida a intercorrência pleural;

- pulmão completamente expandido;

- aspecto claro (seroso) do volume drenado;

- ausência de débito purulento, sanguinolento ou quiloso;

A retirada do dreno torácico é realizada através de anestesia local e no momento de sua retirada, o fio utilizado para sua fixação serve para ocluir a comunicação pleura-parede. É útil solicitar ao paciente que execute uma manobra expiratória não forçada para impedir a entrada de ar pelo orifício deixado pelo dreno $(2,5,8)$.

\subsection{Resumo da técnica $(1,2)$.}

- desfazer as fixações de fita adesiva;

- cortar a amarração e desfazer a bailarina, mantendo o fio tracionado para evitar a entrada de ar na cavidade pleural;

- retirar de forma rápida o dreno;

- amarrar o fio selando a cavidade;

- curativo oclusivo por 24 horas. 


\subsection{O que deve ser evitado $(1,2)$.}

- clampear o dreno no transporte do paciente;

- ordenhar o dreno, pois esse procedimento é pouco efetivo e pode gerar uma pressão negativa muito alta (com exceção dos drenos mediastinais).

\section{Complicações}

\subsection{Precoces}

- hemotórax: pode resultar de laceração em um vaso sanguíneo intercostal. É uma complicação potencialmente séria que pode exigir uma toracotomia de emergência; também há relatos de lesão iatrogênica no ventrículo esquerdo após a inserção do dreno torácico (4);

- laceração do pulmão: é mais comum, naqueles casos em que existe uma sínfise pleural prévia, causada por toracotomia ou processos inflamatórios pleuropulmonares no passado. O risco de lesar o pulmão é maior quando é utilizado o trocater durante a técnica de drenagem;

\subsection{Tardias}

- bloqueio do lúmen;

- hemotórax retido: se um hemotórax não for drenado adequadamente desde o início, pode coagular e dificultar a drenagem torácica. Além disso, pode atuar como um lócus de infecção e resultar em empiema (4).

\subsection{Por uso incorreto da técnica}

Algumas complicações ocorrem pelo uso incorreto da técnica. Assim, apresentamos a seguir, o que não deve ser feito $(5,8,9)$ :

- drenagem rápida de grandes volumes. A rápida mudança nas pressões pleurais e a reexpansão do pulmão anteriormente colapsado podem causar edema pulmonar de reexpansão, uma complicação potencialmente fatal.

- elevar o frasco selo de água ao nível do tórax do paciente, pois o líquido drenado irá refluir para a cavidade pleural;

- desligar uma aspiração sem antes desconectar o sistema de aspiração do respiro do frasco selo de água;

- clampear um dreno que estiver borbulhando quando for trocar ou elevar o frasco, se possível use apenas os dedos para pinçar a extenção. Lembre-se: um dreno clampeado pode provocar um pneumotórax hipertensivo, com balanço do mediastino e parada cardíaca;

- conectar a rede de vácuo direto no respiro do frasco selo de água, use sempre um sistema regulador (frasco de aspiração ou tubo regulador de vácuo).

- introduzir o dreno na parede do tórax ou abaixo do diafragma;

- lesionar a artéria, veia e nervo intercostal se o bordo superior da costela não for usado como referência. 


\section{Considerações finais}

A drenagem torácica é um procedimento comum na prática clínica/cirúrgica. O sucesso dessa habilidade exige um dreno posicionado adequadamente e um sistema de drenagem unidirecional hermético para manter a pressão intrapleural subatmosférica, efetivando a drenagem do conteúdo pleural e reexpandindo o pulmão. A seguir, apresentamos tópicos relevantes que devem ser sempre lembrados todo a vez que o procedimento for realizado (Quadro 2):

Quadro 2 - Tópicos em destaque no capítulo.

\section{DRENAGEM TORÁCICA}

A drengem pleural deve ser considerada em situações patológicas ou pós-procedimento que viole a cavidade pleural.

O calibre do dreno em adultos geralmente é $36 \mathrm{~F}\left(3 / 8^{\prime}\right)$ em hemotórax ou derrames espessos ou $28 \mathrm{~F}\left(1 / 4^{\prime}\right)$ em pneumotórax ou derrames fluidos.

A posição mais recomendada é o paciente em posição semissentada.

O ponto de referncia é o $4^{\circ}$ ou $5^{\circ}$ EIC, na linha axilar média.

No caso de derrames pleurais com drenagem de grandes volumes, devido ao acúmulo de líquido no frasco coletor, opta-se pela drenagem em duplo frasco.

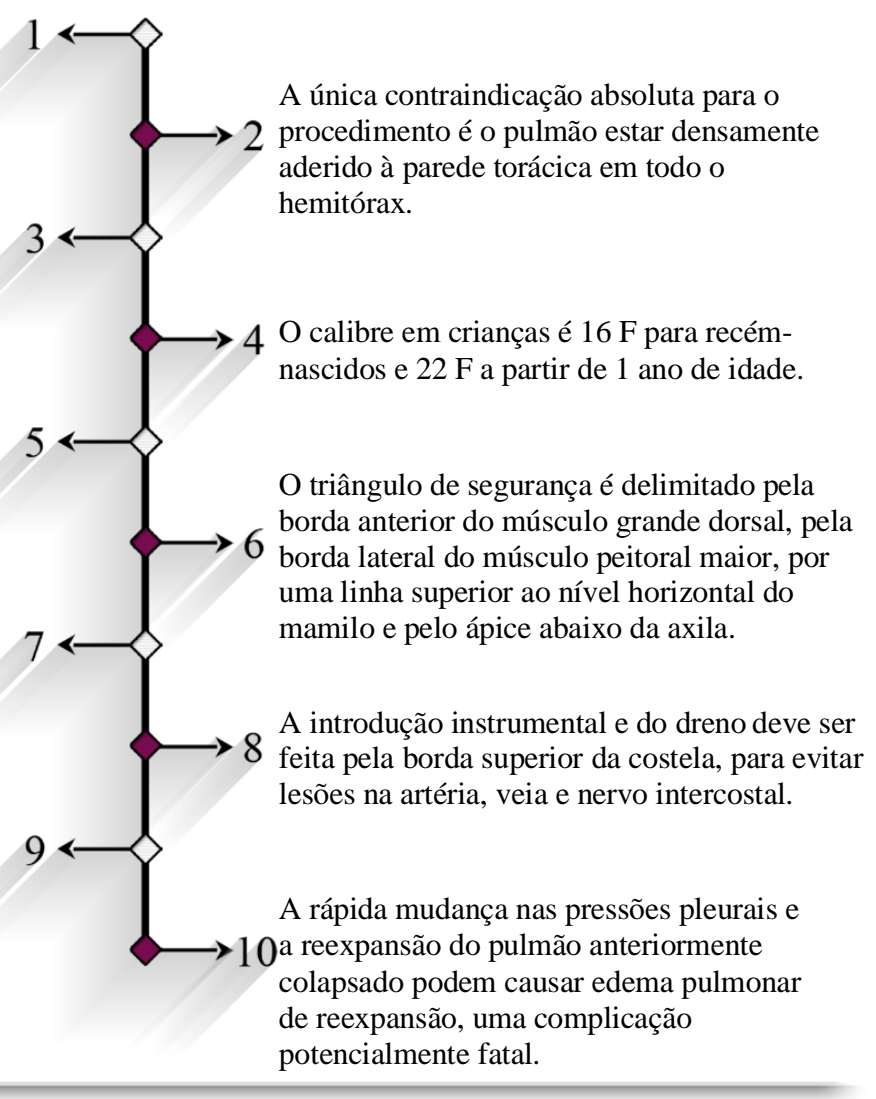

\section{Referências}

1. Di Ciacca L, Neal M, Highcock M, Snowden J, O’Donnell A. Guidelines for the Insertion and Management of Chest Drains. Doncaster and Bassetlaw Hospitals 2009; 29(1): 1-14.

2. Cipriano FG, Dessote LU. Drenagem pleural. Medicina, Ribeirão Preto 2011; 44(1): 70-8.

3. Fallon WF, Wears RL. Prophylactic antibiotics for the prevention of infectious complications including empyema following tube thoracoscopy for trauma: results of a meta-analysis. J Trauma 1992; 33(1): 110-7.

4. Mcelnay PJ, Lim E. Modern Techniques to Insert Chest Drains. Thoracic Surgery Clinics 2017; 27(1): 29-34.

5. Felicetti JC, Corso CO, Mesquita CAC. Drenagem pleural fechada (toracostomia com tubo). In: Nasi LA. Rotinas em pronto-socorro. Porto Alegre: Artes Médicas; 1994.

6. Laws D, Neville E, Duffy J. BTS guidelines for the insertion of a chest drain. Thorax 2003; 58(2): 53-9. 
M. I. Azambuja e M. A. M. de Castro Jr/ Vittalle v. 33, n. 1 (2021) 147-158

7. Demetriades D, Park C. Thoracostomy Tube Insertion. Atlas of Surgical Techniques in Trauma, 2019: $16-22$.

8. Saad Júnior R, Arakaki JSO, Gonçalves R, Polonio IB. Ligas Acadêmicas de Pneumologia e Cirurgia Torácica do Estado de São Paulo. São Paulo: Atheneu; 2014.

9. Felicetti J, Camargo J. Trauma torácico. In: Corrêa da Silva L, Condutas em Pneumologia. Rio de Janeiro: Revinter; 2001: 1053-75. 